University of Arkansas, Fayetteville

ScholarWorks@UARK

Graduate Theses and Dissertations

8-2014

\title{
Durability of Silane Sealer in a Highly Alkaline Environment
}

\author{
Cameron David Murray \\ University of Arkansas, Fayetteville
}

Follow this and additional works at: https://scholarworks.uark.edu/etd

Part of the Structural Materials Commons

\section{Citation}

Murray, C. D. (2014). Durability of Silane Sealer in a Highly Alkaline Environment. Graduate Theses and Dissertations Retrieved from https://scholarworks.uark.edu/etd/2215

This Thesis is brought to you for free and open access by ScholarWorks@UARK. It has been accepted for inclusion in Graduate Theses and Dissertations by an authorized administrator of ScholarWorks@UARK. For more information, please contact scholar@uark.edu. 
Durability of Silane Sealer in a Highly Alkaline Environment 
Durability of Silane Sealer in a Highly Alkaline Environment

A thesis submitted in partial fulfillment

of the requirements for the degree of

Master of Science in Civil Engineering

by

\author{
Cameron Murray \\ University of Arkansas \\ Bachelor of Science in Civil Engineering, 2012
}

August 2014

University of Arkansas

This thesis is approved for recommendation to the Graduate Council.

Dr. W. Micah Hale

Thesis Director

Dr. Ernest Heymsfield

Dr. Richard Coffman

Committee Member

Committee Member 


\begin{abstract}
Alkali-silica reaction (ASR) is a chemical reaction between siliceous minerals present in certain aggregates and alkalis in the concrete pore solution. The reaction can lead to expansion and severe damage in concrete members. One method to mitigate ASR expansion is to use a penetrating sealer such as silane. A set of columns located in a food preparation facility was treated with silane and a complimentary laboratory study was performed. A cleaning regimen involving application of an alkaline cleaner is employed at the facility, followed by rinsing with hot, pressurized water. The purpose of this research is to evaluate the effectiveness of silane when used in this alkaline environment. The research shows that silane was effective at reducing expansion in new concrete, less so when the $\mathrm{pH}$ of the environment is high; other measures were recommended for previously cracked concrete.
\end{abstract}




\section{Acknowledgements}

I would like to thank Steve Avair of Ecolab for his help donating the cleaner used in this study. I want to thank Gary Cox, Lance Logsdon, Mike Davis, and Seth Walters for arranging and implementing our study at their facility. This project taught me about the importance of industry in supporting academia and the advancement of knowledge. Also, I would like to thank Kyle Niemann in particular, for showing us around and being available to us when we visited the facility.

I would like to thank Richard Deschenes, who has been a tremendous help for me through all of the work I have completed at the University of Arkansas, including frequent trips to the facility for measurements. Richard has also challenged me intellectually, both in my classes and research work, and has been an excellent peer. I have learned a lot from his devotion and he has made a major contribution to my work and my understanding of ASR. I would also like to thank Casey Jones for his help in the earliest stages of this work.

I would like to thank the Department of Civil Engineering at the University of Arkansas, in particular my thesis committee; this group has impacted my education and my decision to continue graduate education. I would like to thank Dr. Micah Hale, I am not sure what I would be doing now if it weren't for his impact in my life, but I am quite sure I would not be completing a Master's Degree. He has been instrumental in my decision to become an academician. I look forward to a continuing personal and professional relationship with him for years to come.

Finally I must thank my loving parents David and Kathryn. They are a source of unending inspiration to me, and I owe more to them than I could put into words. 


\section{Table of Contents}

$\begin{array}{lll}\text { Chapter } 1 & \text { Introduction } & 1\end{array}$

1.1 Overview 1

1.2 Research Significance 1

Chapter $2 \quad$ Literature Review 2

2.1 ASR Literature $\quad 2$

2.2 Silane Literature $\quad 5$

2.3 Field and Laboratory Studies in the Use of Silane 9

$2.4 \quad$ Cleaner and Sanitizer Overview 14

$\begin{array}{lll}\text { Chapter } 3 & \text { Experimental Procedure } & 16\end{array}$

3.1 Overview 16

$\begin{array}{ll}3.2 & \text { Field Study } \\ 3.3 & \text { Laboratory Study }\end{array}$

$\begin{array}{lll}3.3 & \text { Laboratory Study } & 20\end{array}$

Chapter $4 \quad$ Results and Discussion 23

4.1 Results of Field Investigation 23

4.2 Results of Laboratory Investigation 28

Chapter $5 \quad$ Conclusions and Recommendations 33

$\begin{array}{ll}\text { References } & 36\end{array}$ 


\section{List of Figures}

Figure 2.1 - Chemistry of silanes (McGettigan 1992) 7

Figure 2.2 - Effect of larger organofunctional group on resistance to attack from hydroxide ions (McGettigan, 1992)

Figure 3.1 - Visible Depth of Silane Penetration 17

Figure 3.2 - Factory Column Cracking $\quad 18$

Figure 3.3 - DEMEC Reference Grid 21

Figure 3.4 - Temperature and Humidity Measurement 22

Figure 4.1 - Field Vertical Expansion Data $\quad 23$

Figure 4.2 - Field Horizontal Expansion Data 24

Figure 4.3 - Field Horizontal Expansion Trends 26

Figure 4.4 - Field Relative Humidity Measurements 27

Figure 4.5 - Lab Horizontal Expansion $\quad 28$

Figure 4.6 - Lab Vertical Expansion $\quad 29$

Figure 4.7 - Laboratory Horizontal Expansion Trends $\quad 30$

Figure 4.8 - Laboratory Vertical Expansion Trends 31

Figure 4.9 - Laboratory Relative Humidity Measurements 32

\section{List of Tables}

Table 3.1 - Concrete Mixture Proportions 


\section{Chapter 1 Introduction}

\subsection{Overview}

Researchers at the University of Arkansas were contacted in 2013 by operators of a local food preparation facility. The facility owners began to notice cracking in several precast columns in 2006. A structural engineer was invited to the plant to evaluate the structural condition of the columns and cores were subsequently obtained for petrographic analysis. The results of the petrography indicated that alkali-silica reaction (ASR) was occurring in the area of the facility where cooked food is present (Randolph 2013). In that area, application of an alkaline cleaning detergent and rinsing with pressurized hot water is required. The research team suggested silane, a penetrating sealer, to reduce internal humidity within the columns and attempt to slow expansion. The field and laboratory investigation into the effects of silane in an alkaline environment are detailed within this paper. Expansion and relative humidity were monitored to provide recommendations to the facility about the extent of expansion and whether silane could arrest the crack growth.

\subsection{Research Significance}

Silane has been studied in the laboratory since the early 1980's (Pfeifer and Scali 1981, Fujii et al. 1989, Berube et al. 1996, Tosun, Felekoglu, and Baradan 2008). However, there are a few studies regarding its use in the field (Olafsson 1983, Imai et al. 1986, Berube et al. 2002), and there are still questions about its durability. While the structure of some silanes provides protection from alkalis (McGettigan 1992), there is very little experimental research analyzing the effectiveness of silane when exposed to alkaline environments, especially in the field. If concrete members are located at facilities using alkaline detergents, silane has been shown to be an option to protect against ASR. 


\section{Chapter 2 Literature Review}

\subsection{ASR Literature}

The first recorded experiences with ASR in the United States occurred in the late 1930's and early 1940's (Stanton 1940). Stanton, of the California Division of Highways, wrote a short paper describing the deleterious effects of a reaction he noticed between a certain combination of aggregates and cement. The problem was first noticed in a section of highway which had experienced considerable expansion, leading to a formal study of the causes. Expansion had caused buckling at expansion joints and Stanton noted the appearance of crazing, or as it would be referred to today in the context of ASR, map-cracking. Aggregates containing chert and shale were used in the concrete. While Stanton recognized the reaction to be occurring between the aggregates and the highly-alkaline cement, the high silica content of the aggregate was not identified as a contributing cause. Stanton's research led to a limit of alkali content in cements used in California.

A second paper was published highlighting the continuing work done by the California Division of Highways on the reaction discovered in the previous paper (Stanton et al. 1942). In this article, Stanton et al. noted that the reactions could be traced to the cement alkalinity and the silica in the aggregates. Stanton et al. coined the term "map cracking" to describe the distresses on affected pavements and structures. The researchers at this point recognized that an accelerated test for aggregate reactivity would be beneficial to quickly pinpoint reactive aggregates. Stanton et al. mentioned the possibility of using a $\mathrm{NaOH}$ solution to accelerate the reaction; which is the basis of the accelerated mortar bar test (ASTM C1260 2007) used today. The researchers rightly pointed out that an accelerated test in $\mathrm{NaOH}$ solution could cause some generally non-reactive constituents of the aggregate in question to go into solution (one of the recognized limitations of 
the test today). Stanton et al. recommended a cement alkali limit of 0.6 percent. This is the demarcation between low-alkali and normal-alkali cements today, although it was noted that lower alkali contents could still prove to be reactive. Ultimately, the Stanton et al. research is regarded as the seminal work in ASR. Although all of the mechanisms were not understood at the time, the test methods they developed have been refined and are used today. Likewise, some of their recommendations are still being implemented.

During the late 1980's research into ASR grew considerably in the United States. Several researchers prepared a detailed report for the Strategic Highway Research Program investigating ASR particularly as it affects highway structures (Stark et al. 1993). Stark et al. discussed the fundamental principles of ASR, evaluation methods (for aggregates and aggregate-cement combinations), and mitigation methods in particular. An extensive database of prior literature was used to develop the recommendations provided in the report. The authors recognized the role of moisture in the reaction; the ASR gel itself actually caused shrinkage of the constituent materials and the addition of moisture lead to expansion. Among the contributions made in the paper was the selection of 80 percent as the minimum required internal humidity to cause expansion of ASR gel. A test developed by the National Building Research Institute in South Africa was recommended to evaluate aggregates for ASR susceptibility; this test would later enter US standards as ASTM C1260. Stark et al. acknowledged that drying existing concrete structures could be a reasonable way to mitigate damage caused by ASR. Tests on pavements were performed using silanes and siloxanes, but these methods were deemed to be "questionable" in their effectiveness at removing moisture from the concrete. Future researchers would continue to use silane to reduce the internal humidity of concrete with some success. Also identified were the three main components present in an environment conducive to ASR 
expansion: reactive silica, high hydroxyl ion concentration (often from $\mathrm{NaOH}$ ), and sufficient internal moisture. Limiting internal moisture would prove to be a common mitigation method for existing structures.

Durand (1993) prepared a report on repair methods for structures damaged by expansion due to alkali-aggregate reactions (AAR, this distinction includes alkali-carbonate reaction). Durand, like Stark et al., identified the necessary conditions for AAR to occur: reactive aggregate, available alkalis, and moisture content above 75 percent ( 80 percent is more commonly cited today). The methods mentioned to mitigate expansion in structures damaged by AAR fall into four categories: protection from moisture ingress, release of stresses through slot cutting, restraint by post tensioning, and chemical impregnation. Durand reported that reducing the moisture level in the concrete was a reasonable way to treat affected structures, even under real-world exposure conditions. Silane was recommended because of its ability to allow moisture to escape while slowing down ingress as well as its flexibility and ability to bond well with concrete. Following these findings, more studies were performed in Canada to test the effectiveness of silane as a treatment for concrete structures damaged by ASR.

ACI report 221.1R-98 (ACI Committee 221, 1998) was an overview of the "state-of-theart" knowledge of AAR up to that time. Again, this report suggests that the three essential factors to maintain AAR are the alkali level, moisture content, and presence of reactive silica; however, the report also indicates the influence of temperature on reaction rate (higher temperatures increase the reaction rate). The report also mentions that an alkali source can be external from the concrete, in particular it is suggested that industrial solutions may provide alkalis sufficient to cause ASR. The report outlines methods for reducing damage to structures which have been affected by ASR. The paper delineates the moisture content needed to sustain ASR expansion at 
80 percent (based on research performed by Stark et al.). To reduce internal humidity, applying a coating or sealant is suggested. The effectiveness of these measures, however, is contingent upon the extent of cracking and the report acknowledged that silanes had been used with limited success in the lab and field. Currently, a new report is being prepared by the committee. This new report will update the recommendations for treating existing structures based on recent research into chemical sealants.

The remainder of this literature review will focus on silane, in particular its method of action and case studies of its use as a concrete sealer. The effects and necessary conditions for ASR are already well documented by organizations such as ACI (as noted above), so an exhaustive review of ASR knowledge is not necessary for the scope of this work.

\subsection{Silane Literature}

Rizzo and Bratchie (1989) described penetrating sealers in terms of their use on concrete highway structures. The paper was published in the Journal of Protective Coatings and Linings; as such, it is a source of specific information about how silane works from scientists outside of the realm of civil engineering. The authors make the distinction between a "penetrating sealant," or "penetrant" (terms that can be used interchangeably), and a "coating." The difference between a penetrant and the other types of sealing materials is the ability of the penetrant to bond as much as $3 / 4$ of an inch into the concrete substrate. Coatings, on the other hand, create a physical barrier on the surface of the concrete and probably allow no vapor transmission. Rizzo and Bratchie describe characteristics of an "ideal" penetrating sealer, the most important characteristics being: the sealant must be chemically resistant (to resist concrete pore solution alkalinity and chlorides), and it must be water resistant but also must allow transmission of water vapor out of the 
concrete. In highway structures, linseed oil has been used widely, but its long term effectiveness is limited by attack from lime in the concrete.

Rizzo and Bratchie go into some detail to define "silane" and explain its mode of action. Today the term "silane" is used interchangeably to describe a variety of chemicals that vary based on the size of the alkyl groups attached to the silicon atom. Silanes are generally applied in a solution with alcohol or water and, as the solvent evaporates, a hydrophobic lining forms on the concrete surface which is bonded to the substrate. This layer repels external water, but allows internal water vapor to escape.

McGettigan (1992) prepared an overview of "silicon-based weatherproofing materials" published in Concrete International. McGettigan uses the term "weatherproofer," rather than describing the compounds as penetrants. Similar to Rizzo and Bratchie (1989), McGettigan describes silanes from the perspective of a chemist, so his paper is a valuable reference for the mode of action of silanes as well as for differentiating between commercially available silanes. McGettigan describes a good weatherproofing material as: being resistant to water, penetrating to a measurable depth, and remaining stable in an alkaline environment, among other characteristics. The most commonly used silicon compound today is what is known as a "Tstructure weatherproofer," which includes silane. The "T-structure," refers to the way the silicon groups bond to the concrete substrate. These weatherproofers contain three silicon functional groups (the groups which are able to bond to the concrete substrate), and one organofunctional group (which creates the hydrophobic layer). The reactions create the hydrophobic layer and are shown in Figure 2.1. T-structure weatherproofers include silanes and siloxanes. McGettigan explains why these compounds are the best weatherproofers for concrete applications based on the characteristics needed from a weatherproofer. In terms of hydrophobicity, a hydrocarbon 
molecule (organofunctional group or "alkyl" group) is present in the structure of the silane or siloxane. The alkyl group is oriented at the opposite side of the molecule from the silicon functional group so that once the silicon functional group bonds with the concrete, the critical surface tension is reduced to less than that of water (making the surface hydrophobic).

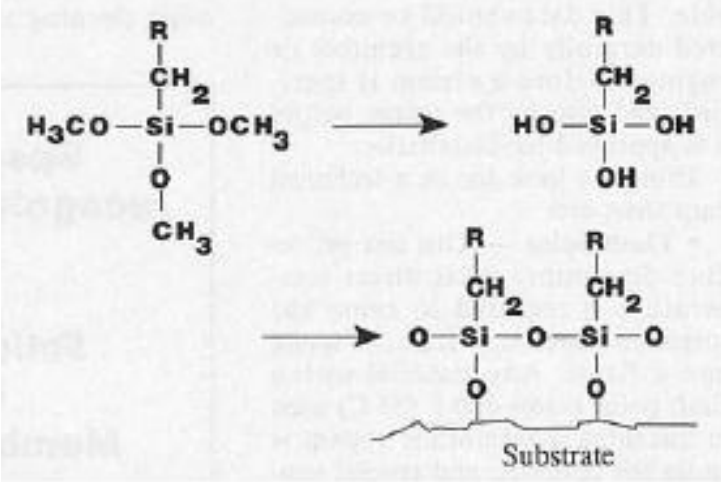

Figure 2.1- Chemistry of silanes (McGettigan 1992)

Penetration depth is another important factor in the effectiveness of a weatherproofer. Penetration depth is related to the durability of the penetrating sealer. Obviously, the density of the concrete plays some role in this, but the chemical makeup of the weatherproofer can affect this depth. McGettigan noted that silanes typically have the highest depth of penetration and that higher concentrations of silane in solution will lead to better depth of penetration. A concern for silicon penetrants is the alkali resistance. Since the $\mathrm{pH}$ of the concrete pore solution often exceeds 13 , the sealant must be able to resist an environment with a large amount of hydroxide ions. Similar to the mechanism by which alkalis react with poorly crystalline silica in aggregates, hydroxide ions can break apart the bonds between adjacent silicon groups in a silane, or break the bond between the silane and the concrete. This attack can be limited by the use of silanes whose alkyl groups are larger (e.g., octyl groups), as shown in Figure 2.2. This research project uses a water based, 40 percent alkylalkoxysilane sealer. Referring to McGettigan's recommendations, this sealer should perform well based on its chemistry. 


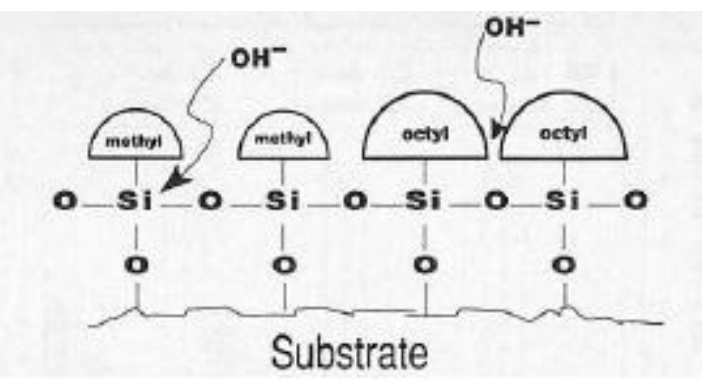

Figure 2.2 - Effect of larger organofunctional group on resistance to attack from hydroxide ions (McGettigan 1992)

McGovern (2000) prepared a short guide for selecting water repellents. McGovern noted that penetrants cannot seal water out of larger cracks, as the molecular size is too small. While the word "penetrant" is used to describe many products, these products vary widely and often the penetration depth of these chemicals is not actually measurable. McGovern lists silanes and siloxanes as the only two classes of penetrant that can "achieve significant penetration." These products bond with the surface of the concrete and create a hydrophobic barrier, rather than a physical coating. Again, it is noted that the effectiveness of these products is a function of the type of alkyl group attached to the silicon group of the molecule. In particular, the larger octyl group is considered the best formulation. Silanes are superior to siloxanes because the molecules are smaller, and are thus able to achieve a greater depth of penetration. Ultimately there is wide variation in products offered as penetrants and often the names for these products are used interchangeably despite differences in their characteristics. McGovern recommends lab testing individual products on the concrete mixture that will be used in the field when selecting a weather proofer. 


\subsection{Field and Laboratory Studies in the Use of Silane}

Silane has been studied as a mitigation method for ASR expansion for at least 20 years.

Reducing the relative humidity of the concrete can slow down or reverse ASR related expansion and silane has been pinpointed because of its cost effectiveness coupled with its ability to penetrate and bond to the surface of concrete without changing the appearance or making the surface slick. This section contains a review of the laboratory and field studies using silane to reduce ASR expansion.

One of the earlier instances of silane in civil engineering literature was NCHRP report 244 (Pfeifer and Scali 1989). The report described testing performed to provide recommendations about various sealing materials, and their application. A number of products were tested, including silane (in particular an alkyl-alkoxysilane) and siloxane. Properties tested included water absorption, chloride intrusion and water vapor transmission. Several series of tests were then performed under varying conditions in order to determine the proper application of these materials. The silane performed well, reducing the intrusion of chlorides and reducing the water absorption as well or better than all other products tested. The researchers noted that more research was needed to evaluate the performance of sealers on cracked concrete and that when the concrete surface is eroded, silane's effectiveness decreased. Silanes became far more common as a concrete sealer in the mid to late 80 's and early 90 's.

Olafsson (1983) performed one of the earliest studies in the use of silanes to mitigate ASR expansion in the field. ASR was a significant problem in homes in Iceland because local cements have high alkali contents and preventative measures weren't taken for interior concrete (preventative measures were common for bridges, dams etc.). Olafsson reviews several efforts to reduce interior moisture in exterior concrete walls including: ventilated panels, shotcrete, 
impregnation of silanes and silicones, and paints. Moisture content was measured using RH meters. The use of silanes and silicones resulted in the most promising improvement, dry ASR gel was observed in cores after treatment and a reduction in RH was observed. The results of the work indicated that silanes were the best and most durable option for walls with map cracking.

Imai et al. (1986) described the deterioration and repair of reinforced concrete bridge piers of the Hanshin Expressway in Japan. Damage was observed in 1979 and by 1982 the damage was considered severe. Concern about cracks extending to the level of the reinforcement led to an attempt to reverse some of the concrete damage. Four sealers were selected; an epoxy resin, a polymer cement paste lining, a silane monomer and a silane oligomer. In preliminary trials the silanes performed best for expansion and mass change in outdoor exposure conditions. This reflects the ability of silane to draw moisture out of concrete during wetting and drying cycles. After filling cracks with epoxy and coating with silane, the crack widths were monitored over time. The researchers found that silane impregnation was effective in controlling the rate of crack growth.

Fujii et al. (1989a) prepared a paper on the use of surface treatments to mitigate AAR damage. The study focused on exposing treated concrete to extreme exposure conditions and then evaluating the treatment methods. Treated specimens were placed outside (in Japan), or were exposed to wetting and drying cycles and temperature changes (100 percent R.H. and $40^{\circ} \mathrm{C}$ to 60 percent R.H. and $20^{\circ} \mathrm{C}$ ). Treatments considered included silane, and after 32 weeks of exposure, the silane samples restricted expansion better than the other methods attempted. The researchers noted that silane's effectiveness increases for members with higher surface area to volume ratios. 
Fujii et al. (1989b) published another study similar to his previous paper, exploring the use of sealers on bridge substructures in Japan. Silane was among the treatment methods explored. Piers and an abutment of a bridge suffering from ASR were coated with several surface treatments and expansion was monitored with strain gauges and by measuring crack width and depth. The group's findings indicated that silane has the potential to inhibit ASR but also noted that after three years of effectively slowing expansion, some surface microcracking did occur.

Berube et al. (1996) studied the effects of silane, oligosilane, polysiloxane, epoxy resin and linseed oil to seal concrete specimens. Small samples were exposed in the lab to harsh cycles of temperature, drying, wetting in salt water, and freeze-thaw, after the application of a sealer. The researchers also sealed some samples after the most severe exposure cycles in order to observe the effects of the sealers on concrete which had already deteriorated. Periodically, mass, length, and relative humidity were measured, and the surface was visually inspected for cracking. Results indicated that silane can be an effective way to seal new concrete that could be susceptible to ASR damage, even in harsh environmental conditions. For samples that had been damaged by exposure cycles, silane was found to be an effective way to "stop concrete expansion and even produce contraction." This paper also discusses the use of silane on highway median barriers, but that research is discussed in more detail in a later paper by the author. Research during the mid-90's in Canada led to much greater interest in the use of silane to counteract ASR expansion in North America.

Grabe and Oberholster (2000) published the results of a study of concrete sleepers on a railroad line in South Africa which had suffered damage due to ASR. Several sleepers were removed for testing and it was discovered that there was some delayed ettringite formation but that ASR was the primary cause of expansion. Researchers cut some sleepers in two and treated 
one half with silane while leaving the other half untreated to observe the effects over time. DEMEC gauges were used to monitor expansion. The halves treated with silane shrank over a period of more than three years while the untreated halves expanded as much as 1.5 percent. Based on this lab testing, 440,000 sleepers were treated with silane. Two sites on the line were chosen for R.H. and dimensional change monitoring. Sleepers treated with silane had R.H. values of 15 percent less on average as compared to untreated sleepers. The researchers concluded that deterioration rate could be reduced with the use of silane treatment.

Berube et al. (2002) sought to replicate the lab observations from their 1996 laboratory study by using silane, oligosilane, and polysiloxane sealers on highway median barriers which had been damaged by ASR expansion. Sealers were applied to the barriers in Canada in two locations in 1991. Expansion was measured with strain gauges and internal humidity and temperature were monitored beginning in 1994. This study was an important milestone in research into surface treatments for ASR damaged structures because the median barriers were studied for a 10 year period after sealing, so the long term effectiveness of the treatments could be evaluated for the first time. The researchers found that silane reduced surface cracking, and could reduce or reverse expansion due to ASR, even in severely damaged sections. Two silanes were tested and one was not as effective as the other, leading to the recommendation that individual silanes must be tested for their effectiveness before large scale use. Another conclusion from this research is that sealers may only be effective for members of small cross section, similar to median barriers.

Lute (2008) published a master's thesis at the University of Texas (UT) which evaluated ASR mitigation techniques using outdoor exposure site testing, and lab testing (depth of penetration, samples stored in the lab under harsh conditions). The depth of penetration testing 
found that a 40 percent solution of silane provided the best depth of penetration. Lute found that sealers can reduce expansion by limiting moisture ingress and lowering the relative humidity in the concrete.

Tosun et al. (2008) published the results of their efforts to mitigate ASR with an Alkylalkoxysilane. The study found that silane treatment reduced expansion from ASR and reduced the water absorption of mortars (using the accelerated mortar bar test). It was determined that silane's depth of penetration and thus its effectiveness was improved when applied to older mortars in a dry condition.

Giannini (2009) provided an update on the continuing evaluation of silane treatment at the UT. This work updated the work performed by Lute, 2008, on the outdoor exposure site at UT, and included field work from highway structures in three states. In two locations, silane was effective in reducing expansion, but relative humidity was difficult to monitor properly. Giannini emphasized the importance of long term expansion monitoring to obtain meaningful results.

In 2010, research at UT and the University of New Brunswick culminated in a report for the Texas Department of Transportation on The Effect of Coatings and Sealers Used to Mitigate Alkali-Silica Reaction (Werhle et al. 2010). This report covered a variety of treatment methods from several research studies around North America. In regards to silane, researchers found that silanes can reduce water absorption and reduce expansion by up to 40 percent. The results indicated that silanes perform better on reinforced concrete members, most likely due to restraint from the rebar cage, and that silanes do not penetrate the substrate as well upon multiple applications (due to the hydrophobic layer imparted by the first treatment). For concrete with ASR within the first 5 in. into the member, silanes can most likely reduce expansion. However, if reactivity is present deeper than $5 \mathrm{in}$. into the member, silanes effects may be diminished. The 
researchers noted that silane performs well at reducing expansion in older specimens but not when applied to members before expansion occurs, although the authors recommended more research to understand this phenomenon.

Knowledge on the use of silane is still evolving, and there is ongoing research into its use for sealing pavements and other structures. The body of knowledge appears to indicate that in many situations, silane is effective at reducing ASR expansion in damaged concrete.

\subsection{Cleaner and Sanitizer Overview}

Since the environment in question for this study is characterized by the use of cleaning detergents and hot water, a review of some basic information regarding cleaning products is necessary. Schmidt (1997) prepared a guide for understanding cleaning products that provides an overview on the concepts behind cleaners in industrial food preparation environments. A typical cleaning regimen involves, in this order, rinsing, cleaning, rinsing, and sanitizing. Cleaning is the removal of "soils" from a surface. The type of soil to be removed depends on the processes in the facility. The type of soils present will determine the cleaning product that is most applicable. In the case of a poultry preparation plant, food waste is the soil of interest, this includes proteins and fats. Removing fats and proteins is difficult, and requires the application of a solution of water and an emulsifier. Alkaline detergents are able to break apart these kinds of soils and allow them to be mixed with hot water and rinsed off. Since these soils are difficult to clean, a strong base like $\mathrm{NaOH}$ or $\mathrm{KOH}$ is generally used, which increases the alkalinity of the concrete pore solution. Another approach to emulsify soils involves using a surfactant, or a chemical compound with a hydrophobic end and a hydrophilic end. Surfactants physically remove soils. A surfactant cleaner could be an alternative to alkaline cleaners because they do not result in high $\mathrm{pH}$ solutions entering the concrete. The disadvantage is that surfactants do not remove difficult 
soils as well as alkaline detergents. This method is unlikely to interfere with the bond between silane and concrete.Heat can accelerate the reaction between alkali and silica but it is impossible to avoid using hot rinse water since the heat promotes solubility of the fats. 


\section{Chapter 3 Experimental Procedure}

\subsection{Overview}

The research program consisted of field monitoring at the facility and a laboratory investigation. In both locations, specimens were subjected to a cleaning regimen consisting of hot water and alkaline soap solution. The materials and procedures used for both parts of the investigation are outlined in this section.

The factory columns are subjected to daily cleaning; columns are soaked with three chemicals for 15 minutes, followed by rinsing in hot $\left(140-150^{\circ} \mathrm{F}\right)$ water. Two of the chemicals are acid sanitizers (consisting mostly of acetic acid and chlorides); the cleaner applied in the greatest concentration is a chlorinated alkaline cleaner (10 percent sodium hydroxide by weight).

In the lab, the alkaline cleaner alone is applied and rinsed in order to replicate field conditions. The sanitizers were omitted in the lab study because they will not affect the occurrence of ASR and would not affect the structure of silane.

The alkaline detergent applied to the columns and lab specimens provides an external alkali source. It is the belief of the research team that this addition of alkalis on a daily basis is responsible for the reaction in the factory. Another consequence of the application of this cleaner is the possibility that it will break the bond between adjacent silane molecules and between the silane and concrete. The structure of some silanes provides protection against the intrusion of alkalis into the chemical structure of silane (McGettigan1992, Rizzo and Bratchie 1989). The silane used in this study was chosen because its structure and composition (consisting of a silicon functional group attached to a large alkyl group) should resist the alkalis (McGettigan 1992). 
The silane used for all parts of this study is a water based, 40 percent (by weight of solids) alkylalkoxysilane sealer. The depth of penetration reported by the manufacturer was 0.24 in. $(6 \mathrm{~mm})$, laboratory verification of this number performed by the research team (Figure 3.1) indicated a penetration depth of 0.22 in. $(5.58 \mathrm{~mm})$ using the procedure outlined in the now expired Oklahoma Department of Transportation standard, OHD L-34 (1982). The silane was applied as specified by the manufacturer on the concrete in the field and the lab to a point of saturation using hand powered pump sprayers.

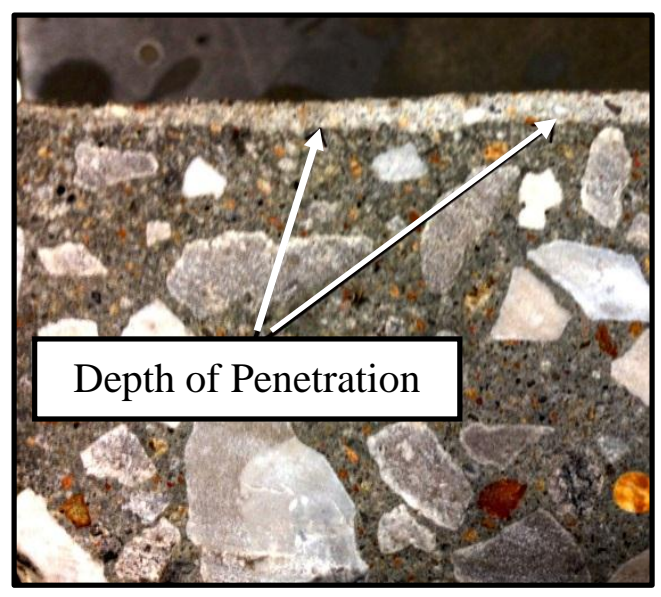

Figure 3.1 - Visible Depth of Silane Penetration (Photograph by C.D. Murray, used with permission)

The goal of using silane is to reduce the internal humidity of the concrete and therefore reduce or reverse expansion. The literature indicates that ASR gel will not expand when the internal humidity of the concrete pore solution is below 80 percent (ACI 221 1998). A laboratory investigation was performed in order to isolate the influence of alkalis on the effectiveness of silane. 


\subsection{Field Study}

The columns in the factory are $2 \mathrm{ft} .(0.61 \mathrm{~m})$ square in cross section and approximately $18 \mathrm{ft} .(5.5 \mathrm{~m})$ in height. The columns are precast and were delivered in 1997; they rest in cast in place pedestals. Cracking was noticed in 2006 and has increased in size and regularity since. There is map cracking primarily in the lower portion of the columns as well as longitudinal cracking at the level of the primary reinforcement (Figure 3.2). Expansion has caused some of the pedestals to show large cracks at the corners. While mix proportions for the columns were not available, petrographic analysis indicates that the coarse and fine aggregate consisted of limestone and sand manufactured from said limestone. The columns potentially contained a small ( 3 to 5 percent by volume of paste) amount of fly ash. The water/cement ratio of the concrete is unclear, however the petrographic analysis indicated it was likely low. The reactive portion of the aggregate was a small amount of chert (a reactive siliceous mineral) found in both the coarse and fine aggregate.

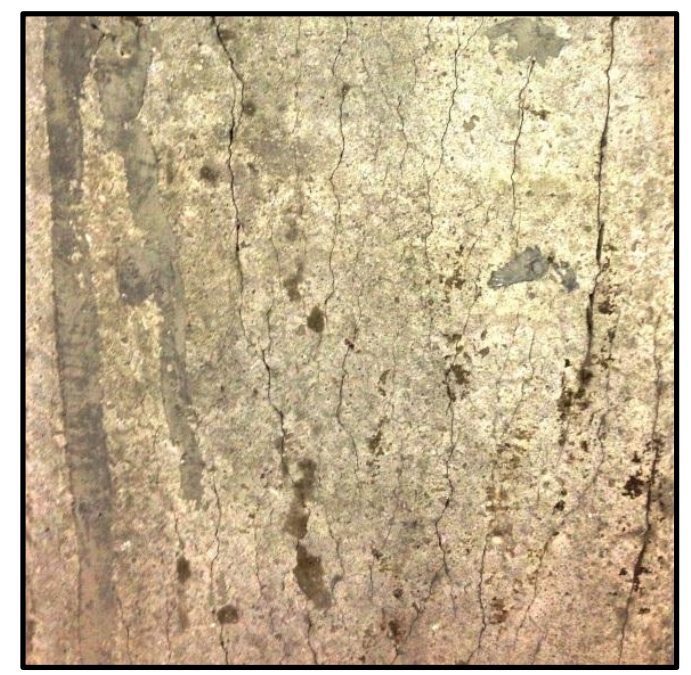

Figure 3.2 - Factory Column Cracking (Photograph by C.D. Murray, used with permission) 
In order to monitor the expansion of the columns, detachable mechanical (DEMEC) strain gauge reference points were placed in the column by drilling and epoxying. The stainless steel reference points have a dimpled end (for the gauge to insert into) and are $2.75 \mathrm{in}$. (70 mm) in length with a diameter of roughly $0.3 \mathrm{in} .(7.62 \mathrm{~mm})$. These points were arranged in a grid measuring $19.7 \mathrm{in.}(500 \mathrm{~mm})$ by $7.86 \mathrm{in} .(200 \mathrm{~mm})$. The columns contained two or three grids on different column faces to provide several measurements in each direction. The distance between these reference points was measured during visits to the plant, and the relative expansion was determined by the percent change from the initial measurement.

In addition to DEMEC points, holes were drilled 6 in. $(150 \mathrm{~mm})$ into the columns to measure relative internal humidity using a handheld humidity and temperature meter. These holes were drilled to be wider than the gauge so that a small $(2 \mathrm{in.}$ [50 mm]) length of PVC pipe (0.5 in. [12.7 mm] inside diameter) could be epoxied in place. The PVC pipe allowed researchers to cap the gauge port and ensured a snug fit for the humidity and temperature probe. These measurements were also taken upon every visit to the facility.

Four columns at the facility were instrumented in the manner outlined above. Three of these columns were located in the cooked food portion of the facility; this portion of the plant is subject to the harshest cleaning and contains the columns with the most ASR damage. Of these three columns, two were coated with silane after the first set of readings. The third was not coated in order to compare the effects of silane on ASR expansion. The fourth column is located in the raw food area of the facility and has very little damage due to less stringent cleaning; this column served as the control column. 


\subsection{Laboratory Study}

The goal of the laboratory portion of this research was to replicate the conditions in the factory in a laboratory setting in order to analyze the performance of the silane in a more controlled environment. Fifteen blocks ( $1 \mathrm{ft} .[305 \mathrm{~mm}]$ cubes) were cast for the program. All blocks were cast outdoors in similar environmental conditions and used the same mix proportions at a w/c of 0.48 (Table 1). The first set of three blocks served as the control specimens. These blocks remained inside the lab at all times and were cast with non-reactive Arkansas River sand (Deschenes 2014). For the remaining 12 blocks, 40 percent of the fine aggregate was replaced with fine aggregate from Jobe-Newman Quarry in El Paso, TX. The Jobe sand is highly reactive and often used to initiate ASR (Thomas et al. 2006, Eskridge et al. 2009). These 12 blocks also included additional alkalis in the form of sodium hydroxide added to the mixing water in order to boost the alkali content of the mix to approximately 1.11 percent $\mathrm{Na}_{2} \mathrm{O}_{\text {eq }}$ (by mass of cement). This additional alkali loading serves to ensure the development of ASR in these blocks (as they have both reactive aggregate and available alkalis). Of the 12 blocks in which ASR was initiated, nine were treated with silane on all sides after at least 28 days of curing.

\section{Table 3.1 - Concrete Mixture Proportions}

\begin{tabular}{crl} 
Material & Weight, $\mathrm{lb} / \mathrm{yd}^{3}\left(\mathrm{~kg} / \mathrm{m}^{3}\right)$ \\
\hline Cement & 750 & $(445)$ \\
Coarse Aggregate & 1500 & $(890)$ \\
Fine Aggregate & 1285 & $(762)$ \\
Water & 360 & $(214)$ \\
\hline
\end{tabular}


All blocks were instrumented in a fashion very similar to the methods described for the columns above. DEMEC gauge points were cast into the fresh concrete at the required gauge length (Figure 3.3). The grid used on the blocks was 7.86 in. (200mm) square. A grid was placed on two adjacent sides of each block.

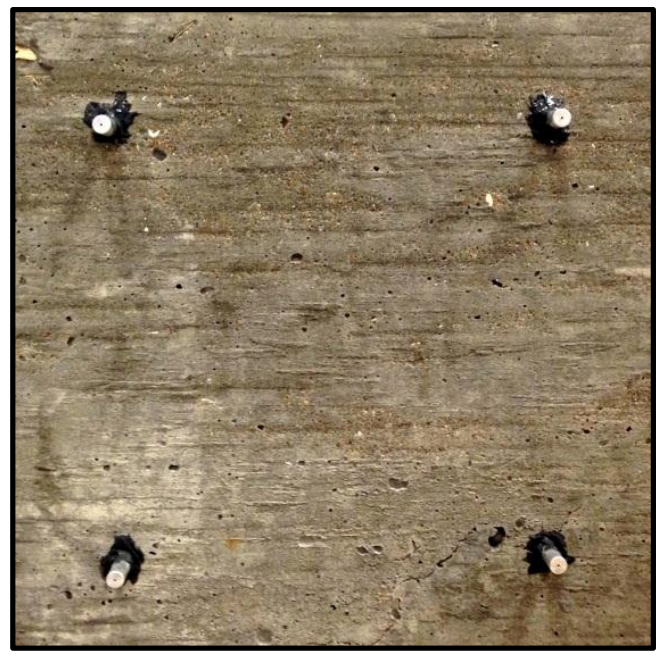

Figure 3.3 - DEMEC Reference Grid (Photograph by C.D. Murray, used with permission) For the temperature and humidity port, a $0.5 \mathrm{in.}(12.7 \mathrm{~mm})$ steel bar coated in grease was placed 6 in. $(150 \mathrm{~mm})$ into the center of the wet concrete; this allowed the bar to be removed when the concrete cured, leaving a port for the temperature and humidity readings (Figure 3.4). This port was capped with a rubber stopper when not in use. Each block contains one such port, located on the top surface. 


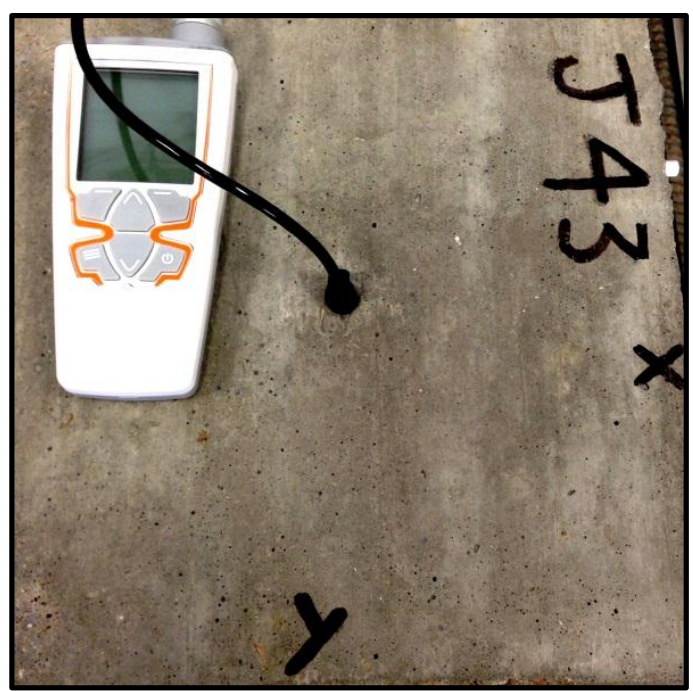

Figure 3.4 - Temperature and Humidity Measurement (Photograph by C.D. Murray, used with permission)

A cleaning regimen similar to that used in the factory was then performed on the blocks. All blocks containing the Jobe fine aggregate were cleaned according to the factory prescriptions. A cleaning cycle consisted of the application of the alkaline cleaner (mixed at the same concentration as in the factory), followed by 15 minutes to allow the cleaner to soak into the concrete, followed by pressure washing with hot water. This cycle would generally be performed approximately 10 times at least once per week. The last set of silane-treated blocks was not sprayed with the cleaning solution, but only hot water, to observe if a breakdown of the silicon bond to the concrete substrate occurred when exposed to high external alkalinity.

Relative expansion, temperature, and relative humidity were measured periodically; these measurements were performed the same way in the laboratory and in the field. 
Chapter 4 Results and Discussion

\subsection{Results of Field Investigation}

Nine trips to the facility were made over the course of 13 months to take humidity and expansion readings. Readings were taken in the same fashion upon each visit except during month 11, when the undamaged control columns were not measured due to construction in the factory. The raw expansion data (expressed as a linear change in percent) is shown in Figures 4.1 and 4.2.

In the vertical direction (Figure 4.1), restraint from the forces acting on the columns likely limited expansion in that direction, in fact, every column contracted in that direction by the end of the study. The magnitude of the vertical change however, was very small. The maximum vertical change measured was 0.0063 percent, which translates to an increase of only $0.001 \mathrm{in}$. (0.0254 $\mathrm{mm})$ over the gauge length.

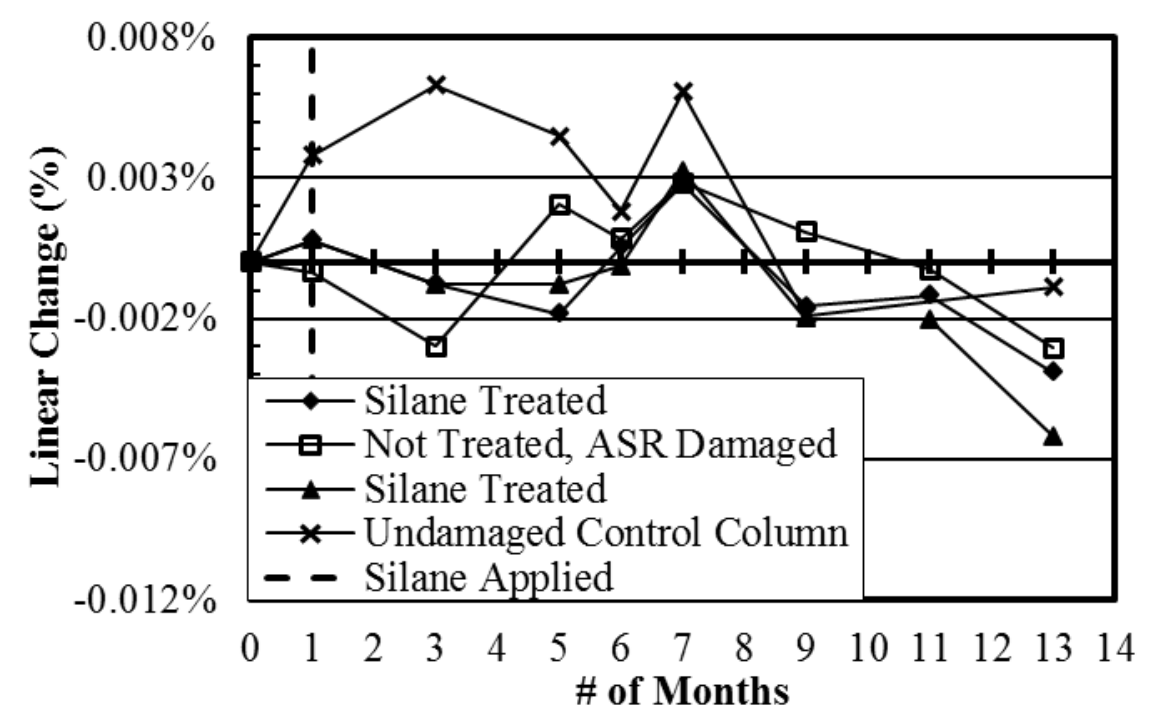

Figure 4.1 -Field Vertical Expansion Data 
Change in the horizontal direction on the other hand (Figure 4.2) showed a clear increasing trend over the 13 month period for the columns affected by ASR. The control column only increased by 0.009 percent or 0.0007 in. $(0.018 \mathrm{~mm})$ over the gauge length for the test period, so it is unlikely that there is deleterious expansion due to ASR in this column, as expected. On the other hand, the columns which have been affected by ASR expanded between 0.028 percent and 0.043 percent by the end of the 13 month observation period. An expansion of 0.04 percent is usually considered the amount of expansion required to initiate cracking, and this is also the limit for deleterious expansion used in the Concrete Prism Test (ASTM Standard C1260 1998). This maximum expansion represents an increase of $.0034 \mathrm{in.}(0.086 \mathrm{~mm})$ over the gauge length, or $0.01 \mathrm{in} .(0.254 \mathrm{~mm})$ over the width of the column.

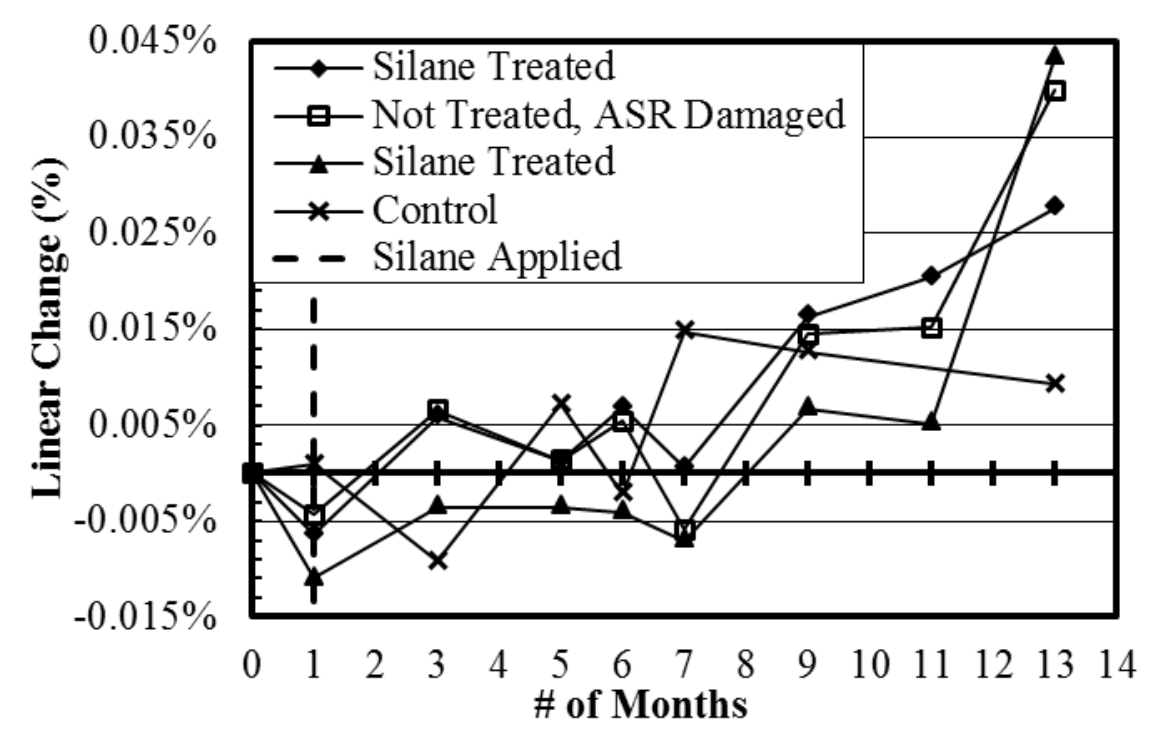

Figure 4.2 - Field Horizontal Expansion Data

There is a clear difference between the expansions measured in the control column compared with the columns which have been affected by ASR. As of the final measurements, expansion in the least expansive ASR affected column was larger than that of the control column by nearly three times. It is then clear that the expansion in the ASR affected columns is ongoing 
and is a continued cause for concern. The average final expansion of the three damaged columns over the observation period is 0.037 percent; this number includes the silane treated columns. Clearly the expansion in this part of the facility is still an issue. As shown in Figure 4.2, the most expansion was measured in one of the columns treated with silane, however it should be noted that these numbers tend to vary upon each reading, so a look at the trends over the 13 month measurement period is prudent and is discussed below.

In figure 4.3, the rates of expansion for the different column groups; silane treated, untreated, and control are compared. The vertical measurements are not compared in this fashion since the rate of expansion in this direction was roughly zero, or less than zero (due to the large gravity forces restraining expansion in that direction). The trend lines in this figure are linear, to show the average rate of expansion for the columns over the observation period. These trends are merely qualitative, and should not be taken as absolute quantities, but are included to ease comparison between the data. As expected the lowest rate of expansion is apparent in the undamaged column, expanding at roughly 0.011 percent/year. This may be somewhat misleading however, because the final expansion in this column was only 0.009 percent. If the expansion in this column were to reach 0.04 percent, silane should still be considered, since little cracking is currently evident. The columns coated with silane did, on average, expand at a lower rate than the untreated column. The rate of expansion in the treated columns was about 0.017 percent/year, as compared to 0.021 percent/year for the untreated column. Despite the slower rate of expansion in the silane coated columns, at this rate, even these could reach the 0.04 percent mark in two and a half years. 


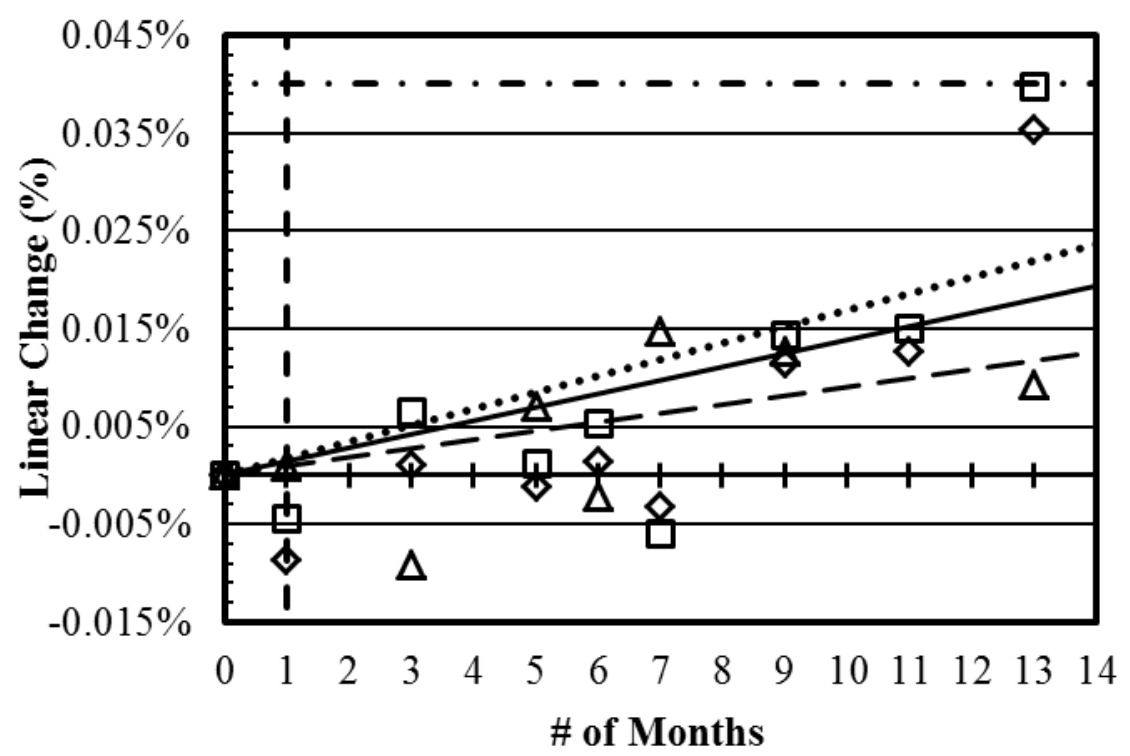

$\diamond \quad$ Silane Treated

․ Not Treated, ASR Damaged

$\Delta$ Control

- - Silane Applied

- - $0.04 \%$ Expansion

Linear (Silane Treated)

...... Linear (Not Treated, ASR Damaged)

- - Linear (Control)

Figure 4.3 - Field Horizontal Expansion Trends

Figure 4.4 contains the relative humidity data collected from the columns. The control column typically contained the lowest relative humidity, as expected since it had no cracking. Relative humidity data from the other columns remained high (between 95 and 100 percent) for the entire observation period. For all columns, the relative humidity increased by at least 2.5 percent after the first measurements. It is possible that the relative humidity port created a conduit for water to flow into, artificially increasing humidity readings. In the future, these ports should be re-drilled at an angle to prevent moisture from collecting. None of the columns reached the 85 percent relative humidity value required to halt expansion, but again these numbers may have been affected by outside moisture. In the case of the field investigation, expansion measurements were a more robust method to monitor the progress of the treatment. 


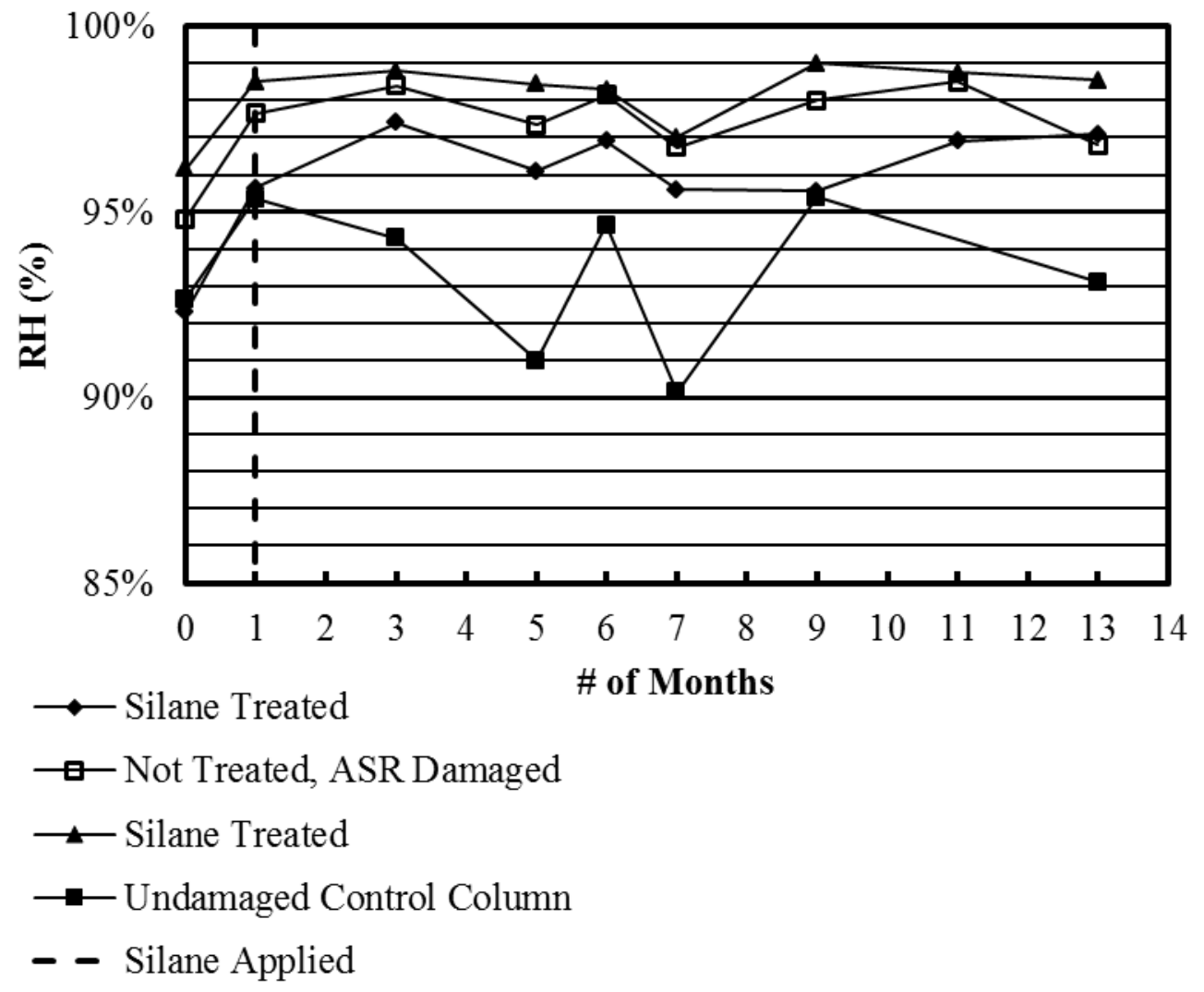

Figure 4.4 - Field Relative Humidity Measurements

While the silane treatment did not reverse or halt expansion in the treated columns over the measurement period, the rate of expansion decreased. The research team believes that despite closing cracks with silicone crack sealer, the larger cracks still allow ingress of alkalis and moisture, limiting the effectiveness of the silane. Cracking in this part of the facility has reached a level where penetrating sealers alone are unlikely to restrain expansion to a noticeable degree. For other columns in the facility, as soon as any map cracking is identified, silane should be applied to prevent these cracks from growing. Recommendations for the future maintenance of the ASR damaged columns are contained in the conclusions of this paper. 


\subsection{Results of Laboratory Investigation}

In the laboratory, measurements were carried out on the blocks for 38 weeks. During this period, the blocks were subjected to 365 cycles of soap and pressure washing (to represent a year of cleaning cycles).

Growth of the blocks in the horizontal direction is shown in Figure 4.5. There was likely some restraint in the horizontal direction (due to the wooden surface the blocks were stored on). As such, 4 of the sets of blocks contracted by the end of the study; the only blocks which had expanded at 38 weeks were the un-sealed blocks in which ASR was initiated (as expected).

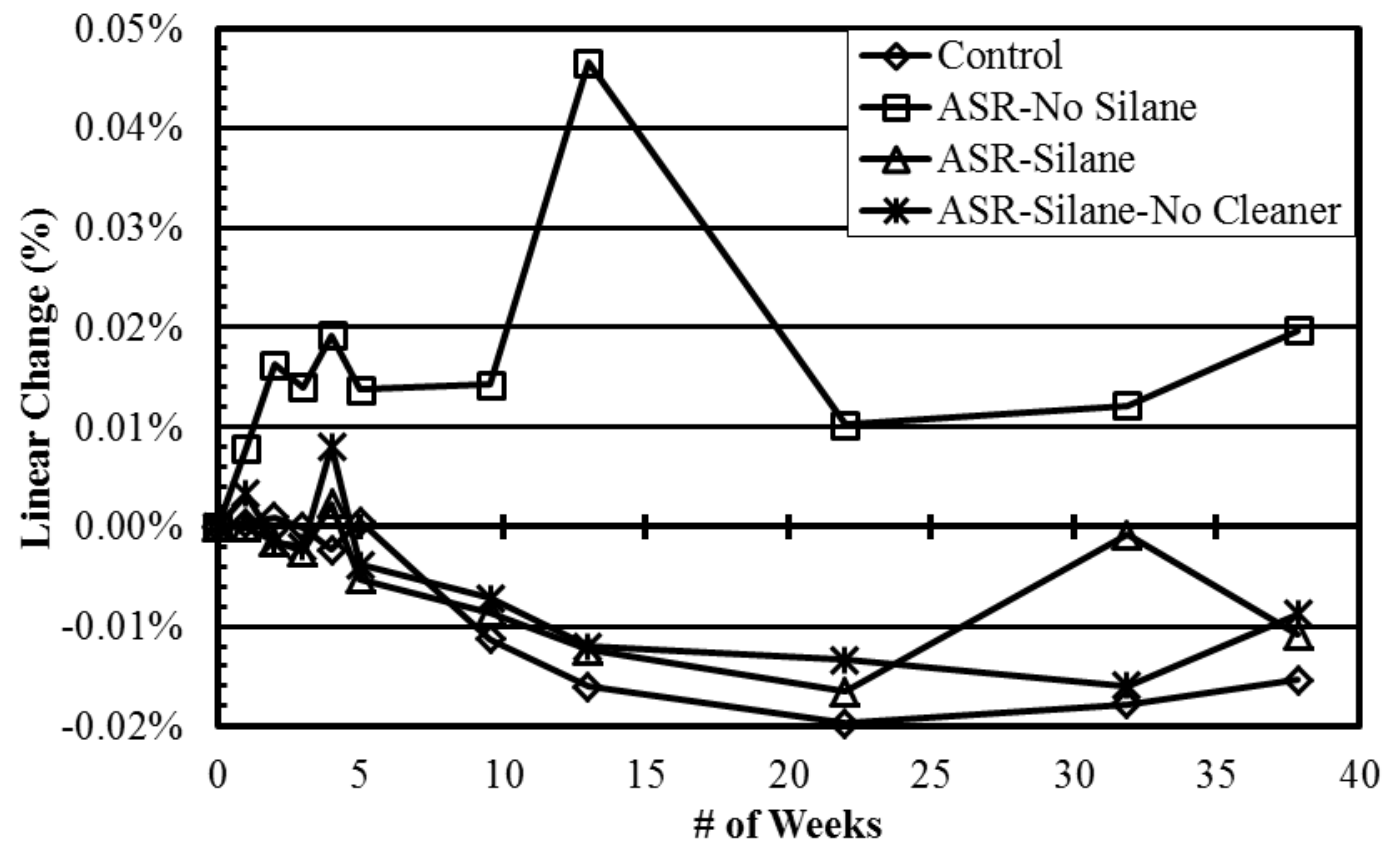

Figure 4.5 - Lab Horizontal Expansion

Vertical expansion in the lab (Figure 4.6) showed a similar pattern. Again, only the samples which were not coated in silane and contained Jobe sand expanded at the 38 week readings. Based on Figures 4.5 and 4.6, it is likely that silane restrained expansion due to ASR. 
The only blocks which increased in height and width were the blocks which had not been treated with silane and contained the reactive Jobe sand.

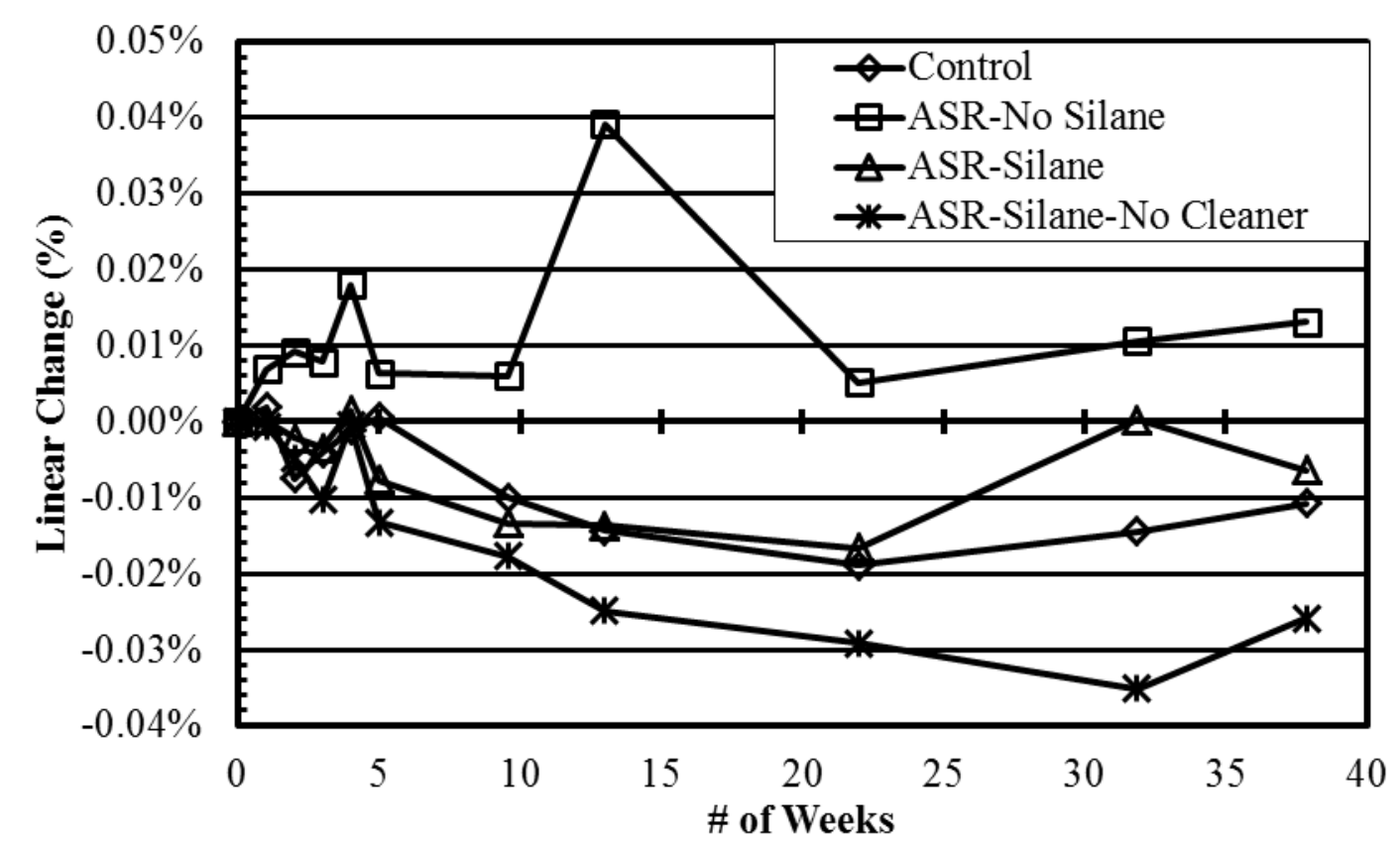

Figure 4.6 - Lab Vertical Expansion

In order to compare the variables of interest (effect of silane in reducing expansion, breakdown of silane due to the alkali-rich environment), trend lines were fit to the data (Figures 4.7 and 4.8). In these figures, the expansion or contraction of the control blocks (containing no Jobe sand and subjected to no cleaning cycles) was subtracted out of the expansions of the other blocks. This removes the effects of temperature (since all blocks were stored in the same environment). By removing the effects of temperature variation, the effects of the silane can be analyzed directly. In both Figure 4.7 and 4.8, the blocks which had not been treated with silane are expanding at a rate of 0.05 percent per year, or enough expansion to initiate cracking in one year of cleaning cycles. No cracks were directly observed, but it is likely that cracking will appear soon. 


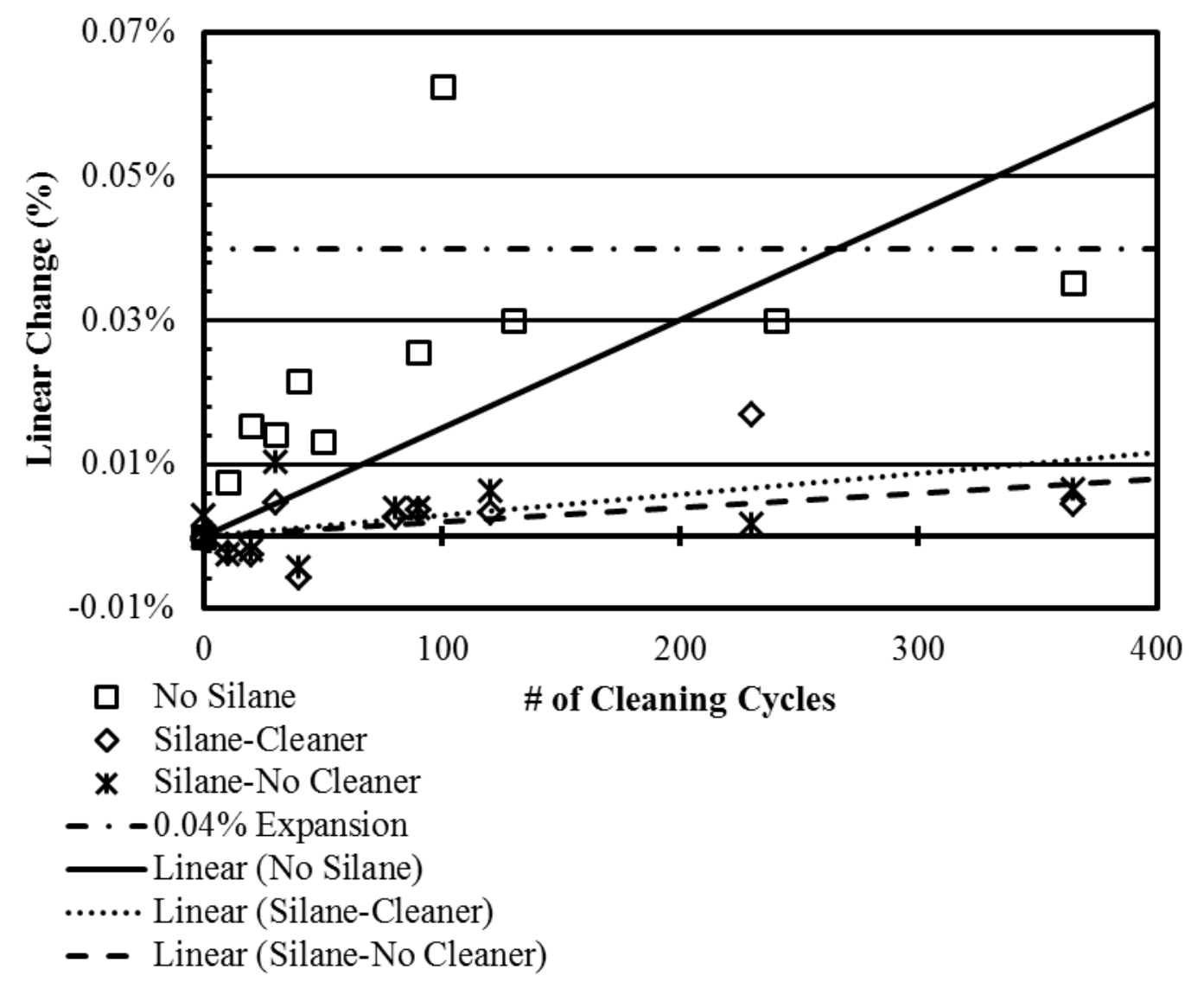

Figure 4.7 - Laboratory Horizontal Expansion Trends

In Figure 4.7 the expansion in the silane treated blocks (whether soap was used or not) was between 0.006 and 0.01 percent per year. This would indicate that silane restricted the expansion of reactive blocks by at least 0.04 percent per year. 


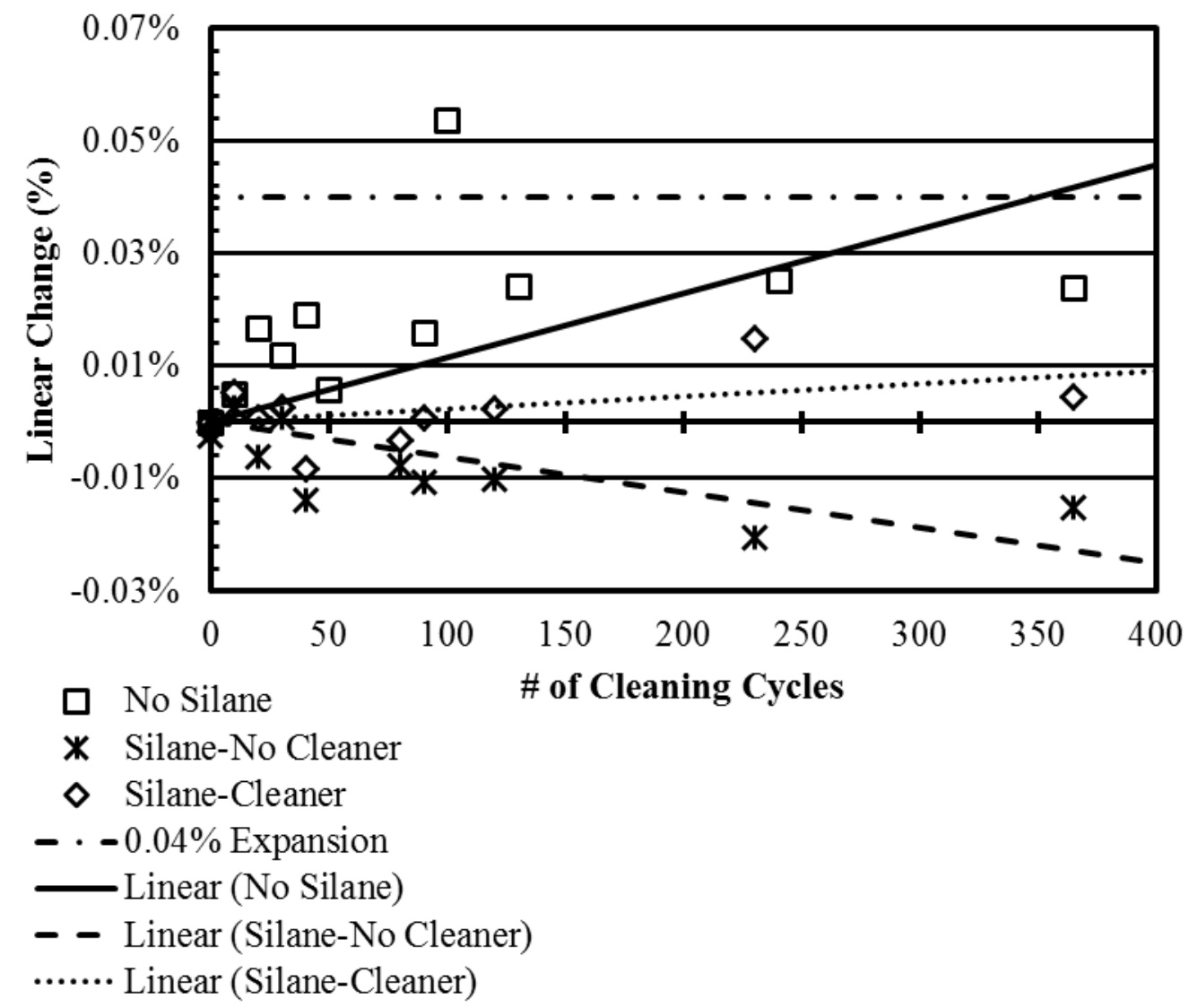

Figure 4.8 - Laboratory Vertical Expansion Trends

In Figure 4.8 this effect is even more noticeable. In the case of the blocks which were not washed with soap but which still had still been treated with silane, contraction occurred, with the final reading being -0.015 percent. On the other hand, silane treated blocks which were cleaned with soap still expanded roughly 0.01 percent per year. This would indicate that the silane bonding can be broken down by the external application of alkalis, as the chemistry of the molecules would suggest. As such, care should be taken when using silanes in highly alkaline environments.

Relative humidity measurements in the lab were less troublesome than in the field, although it was still difficult to discern any measurable difference in humidity between the sets of blocks. Humidity measurements from the lab are shown in Figure 4.9. The control blocks 
remained between $80-85$ percent for the duration of the study, but these were kept dry in an indoor environment. The other sets of blocks generally remained near 85 percent, finishing the study period at around 86 percent.

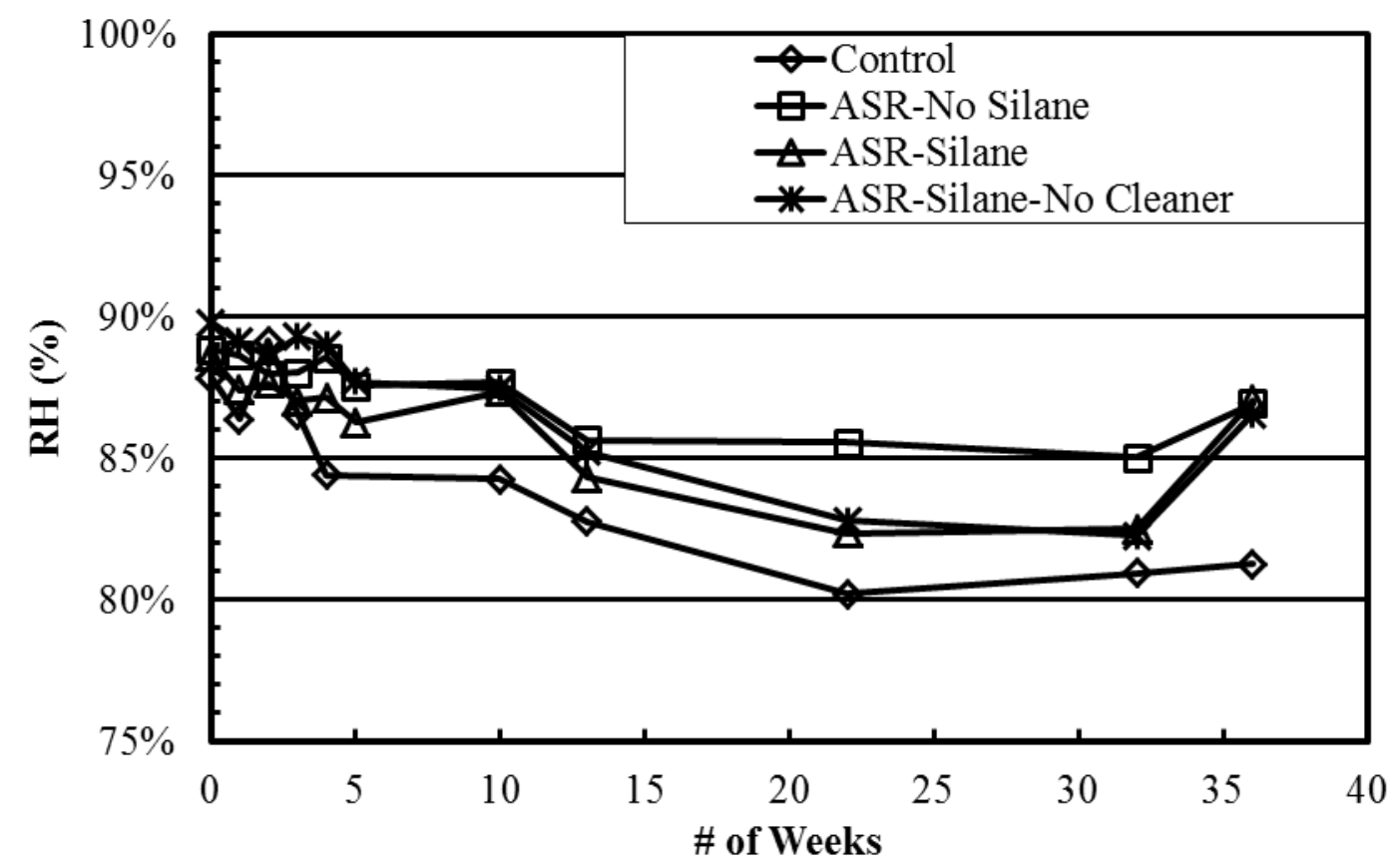

Figure 4.9 - Laboratory Relative Humidity Measurements

The research team believes that expansion was a better indicator of silane performance in this study. Since the blocks were stored indoors and measured at least a day after washing, it is not surprising that relative humidity remained low, despite a clear expansion trend due to ASR. 


\section{Chapter 5 Conclusions and Recommendations}

The results of the laboratory investigation would suggest that silane treatment can be used as a preventative measure in moist environments where ASR is a concern. The blocks in this study were coated with silane before any cracking had occurred and silane arrested expansion.

In environments where alkalinity is a concern, silane should be used with caution. The results of the laboratory study would indicate that the effects of silane can be reduced in as little as a year when exposed to basic solutions on a regular basis. This is a result of the breakdown of silicon bonding by the alkalinity of the environment.

In both the laboratory and the field, humidity measurements were troublesome. Little variation could be observed, and it is possible that humidity in the field was artificially high. There are clear limitations to the method of drilling a humidity port and measuring relative humidity through this port each time. Other researchers have experienced similar difficulties (Giannini 2009). In the case of this study, expansion measurements provided a much more robust method of comparing the effects of ASR in different conditions.

In the field study, the effects of silane treatment were limited. Cracking in the field columns was considerable before the research team was contacted, and the size and extent of cracking provides a mode of ingress for water and cleaner. When observing the columns and the lab specimens, it appears likely that the alkaline cleaner used is exacerbating the effects of ASR and a new cleaner should be used. The facility operators should consider switching to an acid cleaner, a cleaner which uses an oxidizing agent to break up soils, or an enzyme to hydrolyze the 
protein soils, as these methods can be effective at a lower $\mathrm{pH}$. Another option may be the use of chemical surfactants to help suspend soils in water to be rinsed away (Bakka 1997).

Because the effects of silane in the lab, on un-cracked concrete, were so promising, the facility should consider silane as a relatively inexpensive preventative measure for columns which do not yet have significant cracking. Even the "undamaged" control column that was instrumented at the facility exhibits a trend of expansion that could be a concern. It is quite likely that other columns in the facility are experiencing similar levels of expansion and simply haven't begun to crack yet. Certainly, as soon as any map cracking is observed, silane could be an inexpensive method to reduce this expansion and extend the life of the columns. Possibly, silane should even be considered for columns with no visible cracking. When silane is used however, care should be used in selecting a cleaner with a lower $\mathrm{pH}$.

Finally, the columns containing the most damage in the facility have cracked to an extent where surface treatments are unlikely to work. Cracking is extensive and it is likely that cracks extend to the depth of the steel reinforcement. Since the sanitizers used in the facility contain chlorides, corrosion of the reinforcement is a concern to the life of the columns. At this point it is likely that the only option for mitigation left is external restraint. The specific options include (Fournier et al. 2004):

- $\quad$ Removal of the cover concrete, and encasement with reinforced or post-tensioned concrete

- Wrapping the columns in a composite material such as fiber reinforced polymer (FRP) 
- $\quad$ The use of steel straps to compress the columns could be considered, but care should be taken to ensure corrosion of the reinforcing steel does not occur These methods are all unique and uncommon; as such a structural engineer should lead the design process, especially since the structural capacity of the columns may be affected. 


\section{Chapter 6 References}

ASTM Standard C1260. (2007). "Standard Test Method for Potential Alkali Reactivity of Aggregates (Mortar-Bar Method)," ASTM International, West Conshohocken, PA, 2007, DOI: 10.1520/C1260-07, www.astm.org.

ASTM Standard C1293. (2008b). "Standard Test Method for Determination of Length Change of Concrete Due to Alkali-Silica Reaction," ASTM International, West Conshohocken, PA, 2003, DOI: 10.1520/C1293-08B, www.astm.org.

ACI Committee 221. (1998). State-of-the-art report on alkali-aggregate reactivity (ACI 221.1R98). American Concrete Institute. Farmington Hills, Mich.

Bakka, R.L. (1997). Making the Right Choice: Cleaners. Ecolab, Incorporated.

Bérubé, M. A., Chouinard, D., Boisvert, L., Frenette, J., \& Pigeon, M. (1996, August). Influence of wetting drying and freezing-thawing cycles, and effectiveness of sealers on ASR. In Proceedings of the 10th International conference on AAR in Concrete, Melbourne Australia (pp. 1056-1063).

Bérubé, M. A., Chouinard, D., Pigeon, M., Frenette, J., Rivest, M., \& Vézina, D. (2002). Effectiveness of sealers in counteracting alkali-silica reaction in highway median barriers exposed to wetting and drying, freezing and thawing, and deicing salt. Canadian Journal of Civil Engineering, 29(2), 329-337.

Deschenes, R. (2014). Mitigation of Alkali-Silica Reaction in an Interstate Median Barrier (Master's Thesis, University of Arkansas).

Durand, B. (1993). Review of Repair Methods for Structures Affected by Alkali-Aggregate Reactions. Montmorency, Canada: Hydro-Quebec Research Institute, IREQ.

Eskridge, A., Klahorst, J., Klingner, R., and Kreger, M. (2009). Mitigation Techniques for Structures with Premature Concrete Deterioration due to ASR/DEF. ACI MATERIALS JOURNAL 106: 273-280.

Fournier, B., M. A. Bérubé, M. D. A. Thomas, N. Smaoui, and K. J. Folliard. (2004). "Evaluation and Management of Concrete Structures Affected by Alkali-Silica Reaction-A Review." In Seventh CANMET/ACI international conference on recent advances in concrete technology. Farmington Hills, Michigan.

Fujii, M., Kobayashi, K., Miyagawa, T., \& Hisada, M. (1989a). Surface Treatment for Concrete Structures Damaged By Alkali-Aggregate Expansion. In Proceedings, 8th International Conference on Alkali-Aggregate Reaction, Kyoto, Japan (pp. 875-880).

Fujii, M., Miyagawa, T., Tomita, M., Ono, K., Imae, M. (1989b). Effect of coating to inhibit alkali-aggregate reaction of concrete structures. In Proceedings of the $8^{\text {th }}$ International Conference on Alkali-Aggregate Reaction, Kyoto, Japan (pp. 869-874). 
Giannini, E.R. (2009). Field Studies of Mitigation Strategies for Alkali-Silica Reaction in Hardened Concrete (Master's Thesis, University of Texas at Austin).

Grabe, P.J., Oberholster, R.E. (2000). Programme for the treatment and replacement of ASR affected concrete sleepers in the Sishen-Saldana railway line. In Proceedings of the $11^{\text {th }}$ International Conference on Alkali-Aggregate Reaction, Quebec, Canada (pp. 10591068).

Imai, H., Yamasaki, T., Maehara, H., \& Miyagawa, T. (1986, August). The deterioration by alkali-silica reaction of Hanshin expressway concrete structures-Investigation and repair. In Proc. 7th Int. Conf. on Alkali-Aggregate Reactions, Ottawa, Canada, Noyes Publications, NJ (pp. 131-135).

Lute, R. D. (2008). Evaluation of Coatings and Sealers for Mitigation of Alkali-Silica Reaction and/or Delayed Ettringite Formation (Doctoral dissertation, University of Texas at Austin).

McGettigan, E. (1992). Silicon-based weatherproofing materials. Concrete International, 14.

McGovern, M. S. (2000). A clear view of sealers. Concrete Construction, 45(1), 53-58.

OHD-L34. (1982). "Test for Depth of Penetration of Concrete by Penetrating Water Repellent Treatment Solutions," Oklahoma Department of Transportation, Oklahoma City, OK.

Olafsson, H. (1983). Repair of vulnerable concrete. In Proceedings of the Sixth International Conference on Alkalis in Concrete.

Pfeifer, D. W., \& Scali, M. J. (1981). Concrete sealers for protection of bridge structures. NCHRP report, (244).

Randolph, J.L. (2013). Petrographic Examination, ASTM C856, of Concrete Cores from Simmons Foods - Arkansas. CTLGroup Project No. 157553. CTLGroup.

Rizzo, E. M., \& Bratchie, S. (1989). The use of penetrating sealers for the protection of concrete highways and structures. Journal of Protective Coatings \& Linings, 6(1).

Schmidt, R. H. (1997). Basic elements of equipment cleaning and sanitizing in food processing and handling operations. University of Florida Cooperative Extension Service, Institute of Food and Agriculture Sciences, EDIS.

Stanton, T. E. (1940). Influence of cement and aggregate on concrete expansion. Engineering News-Record.

Stanton, T. E., Porter, O. J., Meder, L. C., \& Nicol, A. (1942, January). California experience with the expansion of concrete through reaction between cement and aggregate. In $A C I$ Journal Proceedings (Vol. 38). ACI.

Stark, D., Morgan, B., \& Okamoto, P. (1993). Eliminating or minimizing alkali-silica reactivity (No. SHRP-C-343). 
Thomas, M.D.A., Fournier, B., Folliard, K., Ideker, J., and Shehata, M. (2006). Test methods for evaluating preventive measures for controlling expansion due to alkali-silica reaction in concrete. Cement and Concrete Research 36, no. 10: 1842-1856.

Tosun, K., Felekoglu, B., \& Baradan, B. (2008). "Effectiveness of alkyl alkoxy silane treatment in mitigating alkali-silica reaction." ACI Materials Journal, 105(1).

Wehrle, E. R. (2010). The Effects of Coatings and Sealers Used to Mitigate Alkali-Silica Reaction and/or Delayed Ettringite Formation in Hardened Concrete (Doctoral dissertation, University of Texas at Austin). 